Research, Society and Development, v. 9, n. 8, e844997733, 2020

(CC BY 4.0) | ISSN 2525-3409 | DOI: http://dx.doi.org/10.33448/rsd-v9i8.7733

\title{
Um protótipo usando Arduino para o estudo da lei de Hooke
}

A prototype using Arduino for the study of Hooke's law

Un prototipo que usa Arduino para el estudio de la ley de Hooke

Recebido: 23/08/2020 | Revisado: 30/08/2020 | Aceito: 08/09/2020 | Publicado: 10/09/2020

\section{João Cláudio Nunes Carvalho}

ORCID: https://orcid.org/0000-0001-8619-0869

Instituto Federal de Educação, Ciência e Tecnologia do Ceará, Brasil

E-mail: joao.carvalho@ifce.edu.br

Oséias de Sousa Mourão

ORCID: https://orcid.org/0000-0002-1724-1391

Instituto Federal de Educação, Ciência e Tecnologia do Ceará, Brasil

E-mail: oseias.sousa@ fied.edu.br

\section{Resumo}

Este trabalho apresenta a análise e descrição de um experimento abordando a Lei de Hooke, como uma proposta didática motivadora para a aprendizagem de Física, sustentada na automação de práticas por meio de aquisição de dados com o uso da interface de prototipagem Arduino. O experimento é apresentado de forma detalhada contendo seus objetivos, fundamentação teórica, lista de materiais necessários, esquema de montagem, o código fonte, instruções sobre a execução e coleta de dados. Este experimento foi aplicado em uma turma de estudantes de uma escola de Ensino Médio na cidade de Tianguá, no estado do Ceará, denominada José Ni Moreira, onde percebeu-se uma possibilidade de motivá-los para a aprendizagem de física. A análise dos resultados mostrou que a estratégia de experimentação em Física é uma importante ferramenta de ensino e que a articulação entre essa e o uso de placas para prototipagem, maximizam o desenvolvimento de habilidades associadas aos conceitos trabalhados, de tal forma que os objetivos puderam ser atingidos, tendo ainda, a partir da análise, potencialidade para ser trabalhada em outras realidades escolares.

Palavras-chave: Arduino; Motivação; Ensino; Física.

\footnotetext{
Abstract

This work presents an analysis and description of an experiment about Hooke's Law, as a motivating didactic proposal for the learning of Physics, based on the automation of practices
} 
through data acquisition using the Arduino prototyping interface. The experiment is presented in detail with its objectives, theoretical basis, list of materials included, assembly scheme, the source code, execution of instructions and data collection. This experiment was applied to a class of students in a high school in the city of Tianguá, in the state of Ceará, called José Ni Moreira, where a possibility of motivating them for physical learning is allowed. An analysis of the results shown that the experimentation strategy in Physics is an important teaching tool and that the articulation between this and the use of plates for prototyping, maximize the development of skills associated with the concepts worked, in such a way that the objectives could be reached, having also, from the analysis, potential to be worked in other school realities. Keywords: Arduino; Motivation; Teaching; Physics.

\section{Resumen}

Este documento presenta el análisis y descripción de un experimento que aborda la Ley de Hooke, como una propuesta didáctica que motiva la física, apoyada por la automatización de prácticas a través de la adquisición de datos con el uso de la interfaz de prototipado Arduino. El experimento se presenta en detalle con sus objetivos, fundamento teórico, lista de materiales necesarios, esquema de montaje, código fuente, instrucciones sobre ejecución y recopilación de datos. Este experimento se aplicó a una clase de estudiantes de una escuela secundaria en la ciudad de Tianguá, en el estado de Ceará, llamado José Ni Moreira, donde se percibió la posibilidad de motivarlos para el aprendizaje de la física. El análisis de los resultados mostró que la estrategia de experimentación en Física es una importante herramienta didáctica y que la articulación entre esto y el uso de placas para la creación de prototipos maximiza el desarrollo de habilidades asociadas a los conceptos trabajados, de tal manera que se pudieran alcanzar los objetivos, y también, a partir del análisis, el potencial a trabajar en otras realidades escolares.

Palabras clave: Arduino; Motivación; Enseñando; Física.

\section{Introdução}

Desde o início da história do homem, ele tenta entender o comportamento de tudo que existe na natureza, nessa época o filósofo Tales de Mileto afirmava que a água era a matéria prima básica responsável pela origem do universo. Em toda a história, outros cientistas também se propuseram a explicar essas questões. Nicolau Copérnico, matemático e astrônomo desenvolveu a teoria heliocêntrica do nosso sistema solar, apresentada em seu livro intitulado De Revolutionibus Orbium Coelestium, esse fato foi responsável por um confronto com o 
modelo aceito na época da idade Média pela Igreja Católica, que no caso era o geocêntrico. Devido a influência de Copérnico e outros personagens históricos, Giordano Bruno também interessou-se por temas controversos, entre os quais, a ideia de múltiplos mundos, com diferentes planetas orbitando estrelas.

Galileu Galilei conhecia os trabalhos de Copérnico, e pelo fato de dominar o método científico conseguiu comprovar suas ideias. Se Galileu não soubesse da existência da trompa Holandesa, um 'instrumento para olhar coisas a distância' em viagem a Veneza, muito provavelmente ele não teria feito as descobertas astronômicas e provavelmente ele não seria o pai do modelo heliocêntrico.

É interessante ressaltar que o astrônomo Johannes Kepler com sua elevada sabedoria em matemática, bem como por meio das observações da órbita de Marte, realizadas pelo astrônomo dinamarquês Tycho Brahe, formulou as leis da mecânica celeste.

A ciência desperta muita curiosidade, sendo muito atrativa, porém quando faz parte do currículo de ensino seu entendimento pode ser frustrante, especialmente quando o ensino é eminentemente teórico. Por outro lado, é provável que métodos de ensino que se utilizam de experimentos sejam muito mais eficientes. Um exemplo histórico interessante foi do britânico Michael Faraday, que mesmo sem educação científica formal, foi um cientista experimental que contribuiu para a formulação da teoria eletromagnética, bem como diversas outras descobertas e invenções, em especial a indução eletromagnética. Ao longo do tempo, com abundância de descobertas científicas se acelerando e devido a existência de inúmeras equações matemáticas para descrever os modelos que foram sendo propostos, o ato de transformar o conhecimento científico em conhecimento escolar, para que possa ser trabalhado pelo docentes e compreendido pelos alunos foi sendo cada vez mais necessário, esse instrumento é conhecido como transposição didática (Chevallard, 2013). Além disso, metodologias de ensino facilitadoras que se aproxime da natureza instigante da Ciência são cada vez mais indispensáveis (Dewey, 2015; Carvalho et al., 2020). A inserção de experimentos no ambiente escolar, por meio do laboratório de ciências, desenvolve o ato de ensinar, ampliando as ferramentas pedagógicas.

Quando se faz medidas necessita-se de instrumentos para aferição que sejam adequados e precisos. A precisão das medidas, é dependente das componentes físicos do aparelho, bem como da forma como a medida é feita. Em laboratórios didáticos a precisão dos instrumentos não é um requisito, já que o intuito não é confirmar uma determinada teoria, mas corroborar por aproximação determinadas leis já bem consolidadas, no intuito de melhorar a o entendimento durante o curso de Física. 
Devido ao progresso da eletrônica, vários sensores, dispositivos e microcontroladores têm sido frequentes em processos de obtenção de dados experimentais, mesmo que para fins didáticos, mostrando uma eficiência jamais vista de modo geral. Por meio da utilização de códigos escritos em alguma linguagem de programação, a obtenção de dados por intermédio de aparelhos eletrônicos tem impulsionado o ensino e obviamente a pesquisa, porque experimentos que levam um tempo considerável de acompanhamento e obtenção de informações podem ser automatizados e ter seus dados acumulados para estudos posteriores.

Para utilização em processos de ensino muitas placas eletrônicas têm surgido ultimamente, como o Arduino e o Raspeberry Pi, este apresentando uma capacidade de processamento bem maior, já o Arduino é utilizado sobretudo em sistemas de automação por meio de sensores.

Os diversos sensores e a forma com a qual os dados podem ser ajustados fazem desse tipo de microcontrolador um instrumento muito útil na preparação de experiências de Física, seja para certificar uma teoria, ou mesmo para fazer previsões, ou distinguir padrões fenomenológico no campo de ação da Física, como por exemplo, as marés atmosféricas abordado por (Carvalho et al,. 2014), o qual utilizou a placa Arduíno para obtenção de dados atmosféricos.

A abordagem de conteúdos estudada de forma completamente teórica é monótona, mas quando são debatidos por meio do uso de práticas experimentais, a curiosidade emerge provocando mais motivação. Dentro das inúmeras possibilidades de utilização do Arduíno, o docente de Física é beneficiado da qualidade dos dados obtidos, que no contexto didático apresenta uma margem de erro praticamente desprezível. Um exemplo que confirma essa afirmação é o trabalho do (Monk, 2014), no qual um experimento para estimativa da aceleração da gravidade é apresentado. Com a utilização de um Arduíno Mega, um valor de $9,778 \mathrm{~m} / \mathrm{s}^{2}$ foi obtido, apresentando um desvio padrão de $0,012 \mathrm{~m} / \mathrm{s}^{2}$. Vale salientar que este valor é praticamente igual ao obtido pelo Observatório Nacional. O emprego do Arduíno é uma forma barata para desenvolvimento de práticas experimentais de Física com excelente precisão, sem obrigação de equipamentos mais caros, típicos dos laboratórios de Física.

O largo uso do Arduino se deve, entre outros fatores, a sua enorme versatilidade, o que estimula o compartilhamento de experiências, projetos, códigos e diversos outros recursos, que são expostos, experimentados e debatidos em diversos fóruns e tutoriais na internet. Além disso, temos na literatura, trabalhos como o de Simon Monk, 30 Projetos com Arduino (Oliveira, 2010) que apresenta pequenos projetos divididos em capítulos, explorando as funcionalidades do Arduino e seus componentes. Entretanto, esse tipo de 
publicação somente destaca o passo a passo para a criação de projetos lúdicos, enquanto aqui, nosso objetivo é apresentar a automação de um experimento de Física com intuito pedagógico, ou seja, a compreensão dos conceitos físicos.

Diante deste cenário, iremos aqui discutir a implementação e o uso do Arduino na aplicação de um experimento para a análise da lei de Hooke, além de avaliar a aprendizagem e motivação dos alunos, dando subsídios técnicos e teóricos para professores/pesquisadores de Física.

\section{Metodologia}

Através de exposições de Robótica Educacional, trabalhadas com estudantes de uma escola de Ensino Médio na cidade de Tianguá, no estado do Ceará, denominadas José Ni Moreira, percebeu-se uma possibilidade de motivá-los para a aprendizagem de física. A motivação dos alunos é um fator importantíssimo como um elemento que impulsiona a aquisição de conhecimentos, nesse contexto o uso de ferramentas tecnológicas pode ser importante nesse sentido. Notou-se, a princípio, que o uso constante de interfaces eletrônicas na montagem de projetos despertava a curiosidade, impelindo os alunos a concretizar suas tarefas. $\mathrm{O}$ aspecto estimulado durante a execução das atividades foi o mais livre possível, ou seja, estimulou-se o uso e manipulação dos equipamentos eletrônicos e sensores.

Antes de avançarmos é fundamental fazer referência sobre a natureza deste trabalho, que consiste em uma descrição sobre as condições, orientações e aplicabilidade no uso de experimentos assistidos por computador com o uso do Arduíno aliada ao estudo da lei de Hooke, que é um dos primeiros tópicos apresentados aos alunos na disciplina de Física, particularmente quando o professor trabalha aplicações das leis de Newton. A proposta aqui apresentada pode ser trabalhada na forma de uma sequência didática, conforme proposto por recentes trabalhos (Carvalho, 2020; Fontele, 2020), entretanto para isso alguns ajustes devem ser realizados a critério do professor. Portanto, não iremos apresentar aqui inovação teórica no campo da educação, mas sim uma automatização de práticas de conteúdos de Física.

Os códigos de programação serão apresentados no texto. Certamente são necessários ajustes, de acordo com o experimento em particular, mas a base de programação é sempre a mesma. Mais um motivo para a importância que vem sendo dada ao estudo do sistema Arduino no ensino de Física. 


\section{Experimento da Lei de hooke}

Diversos aparelhos de medição empregam molas como parte de seus instrumentos mecânicos, como por exemplo algumas balanças, dinamômetros e aparelhos de medidas elétricas. Isso é possível, pelo fato da mola sofrer deformação em virtude da força aplicada e consequentemente sofre um deslocamento.

Ao se aplicar uma força em uma mola, dependendo da constante elástica da mesma e da intensidade da força, uma compressão ou distensão pode surgir na direção da força. Essa deformação provocada na mola por conta da ação de uma força ficou conhecida no século XVII como a lei da elasticidade, a qual foi descoberta pelo físico inglês Robert Hooke. Obviamente, esta relação aplica-se a outros tipos de materiais que manifeste algum grau de distensão ou compressão. A relação mais usual para esta lei é:

$$
F=k \cdot x
$$

$F$ é a força em newtons (N), $x$ a deformação que pode ser calculada em metros (m) e $k$ é a constante elástica da mola $(\mathrm{N} / \mathrm{m})$.

\section{Montagem do experimento}

Para realizar o experimento, é necessário utilizar um dinamômetro simples, o intuito inicial aqui é saber o valor da força peso para diferentes objetos. Por meio do Arduino será possível analisar o peso na superfície da Terra, bem como em qualquer outro astro de nosso universo.

\section{Materiais e componentes necessários:}

- Dinamômetro

- Massas aferidas

- Arduino

- Resistor $10 \mathrm{k} \Omega$

- Protoboard

- Jumpers

- Laser

- LDR 
No monitor serial será possível verificar o peso na Terra, na Lua, no Sol e nos demais planetas do sistema solar, incluindo Plutão (Figura 1).

Figura 1 - Para a execução deste experimento é necessário desmontar a parte superior do dinamômetro, se isso não for possível será necessário serrá-lo totalmente na superior, isto para inserir o Laser e o LDR. Além disso, um alvo branco deve ser fixado na espira inferior (a última) a fim de refletir a luz do laser na direção do LDR. Sugestão: caso não caiba o Laser e o LDR no interior do dinamômetro você pode fixar o LDR na parte externa do dinamômetro, paralelo ao Laser.

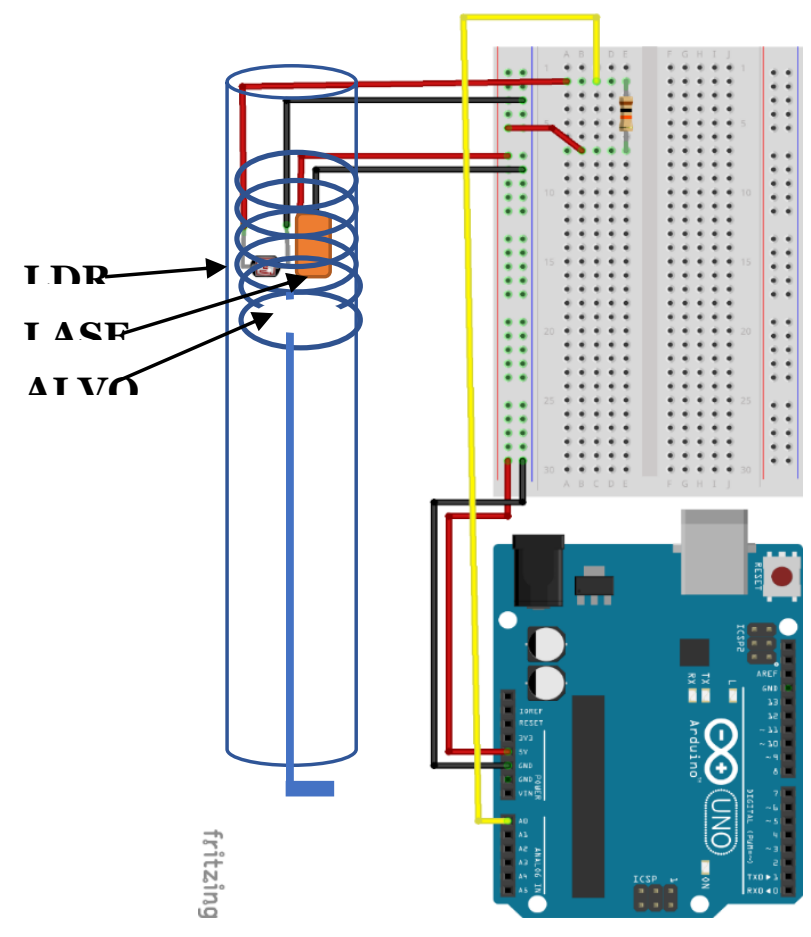

Fonte: Imagem do autor extraída e editada no Fritzing.

Para a execução do experimento é importante desmontar o dinamômetro para fixar o módulo laser/LDR em uma posição a, aproximadamente, $1 \mathrm{~cm}$ acima da extremidade móvel inferior da mola do dinamômetro. Essa mesma extremidade deverá estar pintada com cor clara, o que permite a reflexão do laser e devida sensibilização do LDR. Veja a Figura 1.

Para iniciar o experimento fixa-se verticalmente, em um suporte, o dinamômetro e prepare-se as massas que serão utilizadas. 


\section{O código}

O código utilizado para o experimento foi o seguinte:

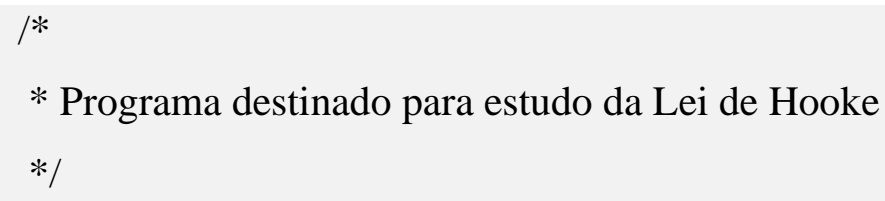

Serial.println("..... "); delay(2000);//Pausa de 2 segundos

Serial.println(". ..");

Serial.println("FORCA PESO");

Serial.println(".... ..");

delay(2000); //Pausa de 2 segundos

Serial.println(" .");

Serial.println("MEDINDO O PESO DE MASSAS AFERIDAS");

Serial.println(". ."); delay(1000); //Pausa de 1 segundos

Serial.println("Calibrando o dinamometro");

$\operatorname{delay}(2000)$;

Serial.println("posicione o dinamometro na posicao inicial"); $\operatorname{delay}(5000)$; 


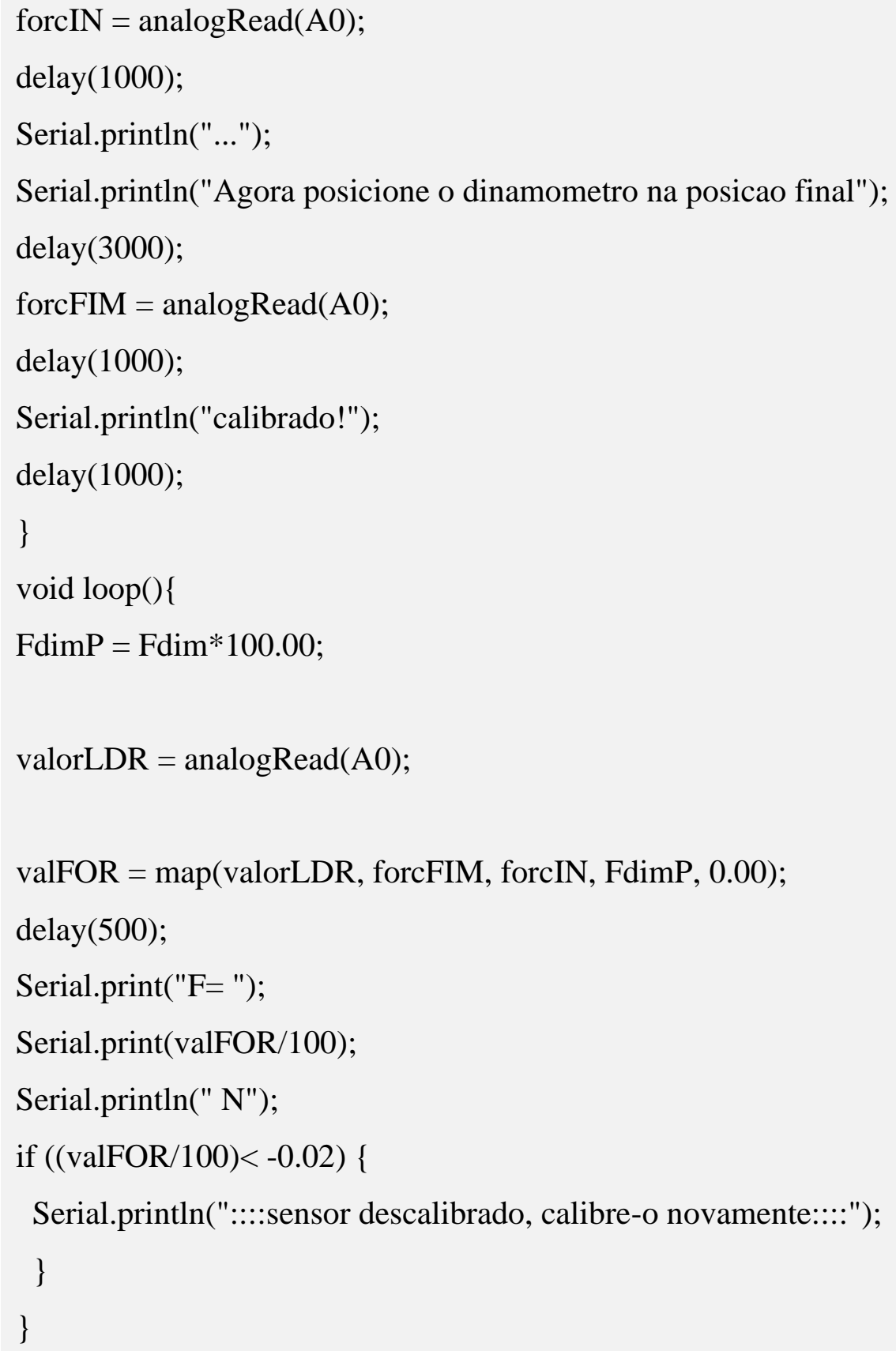

Uma calibração do dinamômetro é realizada antes de começar as medidas. Por conta de possíveis variações na posição do LDR e também devido as variações de luminosidade no LDR. No caso do dinamômetro que foi utilizado aqui utilizamos no código $F \operatorname{dim}=2$, isso significa que o programa calcula adequadamente força de até $2 \mathrm{~N}$. Para outros dinamômetros é necessário verificar seus valores máximos.

Após a conferência de toda a montagem , bem como o uso e/ou criação do código no software do Arduino IDE, faz-se o upload para o sistema. Inicia-se o Monitor serial, é importante perceber que logo no início que é exibida no Monitor serial, a seguinte mensagem: 


\section{"Calibração do dinamômetro"}

Este é o instante a partir do qual, deve-se efetuar uma calibragem no dinamômetro para só então dar início as medidas. A mensagem seguinte será:

$$
\text { "posicionar o dinamômetro na posição inicial" }
$$

Logo após a mensagem ser exibida, têm-se apenas 5 segundos para posicionar o dinamômetro em sua marca inicial, ou seja, sem nenhuma massa suspensa em sua extremidade inferior aguarde até que surja a mensagem para o próximo procedimento. Caso não consiga efetuar este procedimento dentro dos 5 segundo reinicie o monitor Serial, ou o Arduino, e repita. Ao findar os 5 segundos, a nova mensagem será exibida:

"Agora posicione o dinamometro na posicao final"

Este é o último procedimento e consiste em apenar estender a mola do Arduino até sua marca máxima, correspondente ao valor máximo da força que o mesmo pode registrar. Também deverá ser mantida essa posição durante os 5 após a exibição da mensagem.

A partir daqui pode-se calcular o peso da massa escolhida. Caso o dinamômetro esteja mal calibrado, um aviso irá surgir:

$$
\text { "::::sensor descalibrado, calibre-o novamente::::" }
$$

Quando isso ocorrer, reinicia-se o monitor serial ou o Arduino e refaz-se os passos anteriormente descritos. Quando se coloca uma massa no dinamômetro nenhum valor aparecerá no Monitor até que você pressione a letra inicial correspondente ao corpo celeste em que supostamente a massa aferida estivesse. Para saber a massa em qualquer outro corpo celeste basta ajustar o valor da aceleração gravitacional e fazer o ajuste no código.

Um professor pode propor em sala de aula o preenchimento de uma tabela, onde em uma coluna coloca-se o nome do corpo celeste e na segunda coluna o peso da referida massa calculada neste corpo.

Ao estudar a Lei de Hooke, os valores calculados no dinamômetro serão distintos para cada uma das massas porventura utilizadas. A deformação na mola (x) do dinamômetro não é a mesma para cada um dos dinamômetros utilizados, e consequentemente teremos para cada um deles diferentes valores para a constante elástica. Porém, por conta da lei de Hooke, a mola 
apresenta a mesma constante elástica $(\mathrm{k})$ para mais de um par, força versus deformação, em uma relação linear, conforme a equação $\mathrm{F}=-\mathrm{kx}$.

\section{Zona de Desenvolvimento Proximal, Aprendizagem Significativa e Transposição Didática.}

Nesta seção, apresentam-se as características de três importantes conceitos desenvolvidos respectivamente por Vygotsky, Ausubel \& Chevallard.

Entre as diferentes contribuições que derivam dos trabalhos desenvolvidos pelo Lev S. Vygotsky podemos destacar a questão da zona de desenvolvimento proximal (ZDP). Ela pode ser definida como a distância entre o nível de desenvolvimento real, composto por funções já consolidadas pelo indivíduo, que lhe deixam efetuar atividades com autonomia, e o nível de desenvolvimento potencial, caracterizado pelas funções que, segundo Vygotsky, estariam em estágio embrionário e não amadurecidas (Vygotsky, 2007).

Aprendizagem significativa é aquela em que ideias descritas através de símbolos interagem de maneira não-literal, ou seja, não ao pé da letra com aquilo que o aprendiz conhece. Além disso, essa interação precisa se relacionar com conhecimentos específicos relevantes(subsunçores) já existentes na estrutura cognitiva do estudante. Essas estruturas cognitivas, segundo Ausubel, são como estruturas hierárquicas de conceitos, os quais são representações de experiências sensoriais dos alunos (Valadares, 2011). A ocorrência da aprendizagem significativa é uma consequência do desenvolvimento e mudança dos subsunçores. Partindo de um conceito já assimilado pelo estudante, o conhecimento pode ser arquitetado de modo a conectá-lo com novos conceitos, promovendo o entendimento dos novos elementos, dando um significado real ao conhecimento adquirido.

As novas ideias só são aprendidas e retidas de forma eficaz caso façam referências a conceitos e hipóteses já existentes, que proporcionam as âncoras conceituais. Existem vários exemplos no contexto do ensino de física desse processo, como por exemplo, ao se apresentar os conceitos de velocidade e aceleração, é necessário que os conceitos de medidas de posição e tempo já existem na estrutura cognitiva do estudante, os quais servirão neste caso como os subsunçores para novas informações. Um outro exemplo interessante é quando o professor apresenta o conceito de interação de ondas eletromagnéticas com a matéria, onde aqui os subsunçores necessários são os conceitos de quantidade de movimento, sua conservação e as colisões. No caso do estudo das leis de Newton e seu conceito básico de força, os subsunçores necessário são justamente os conceitos de velocidade e aceleração 
Um outro conceito interessante de mencionarmos aqui é a questão da transposição didática. Nossa sociedade se manifesta por meio de sua cultura e todo conhecimento é decorrente da aquisição de saberes que foram acumulados em múltiplos contextos sociais e históricos. É preciso perceber que parte disso não foi produzido para ser ensinado, mas sim para ser utilizado. A passagem do conhecimento considerado como útil em um conhecimento como algo que possa ser ensinado e aprendido é segundo Yves Chevallard (1991) definido como transposição didática do conhecimento. Esse trabalho de transposição é iniciado desde a preparação do conhecimento para sua divulgação no meio científico, que é justamente o primeiro passo no sentido de tornar aquele conceito compreensível. Dessa forma, a transposição pode ser percebida como um conjunto de ações cujo objetivo é transformar um saber científico (construído pelos cientistas) em saber ensinável (saber presente nos livros didáticos) (Fernandes Sobrinho, 2015).

\section{Resultados e Discussão}

As aplicações da atividade do experimento foram realizadas no Liceu de Tianguá Ceará, com o objetivo de averiguar a relevância das atividades e do método. Nos testes houve a participação de alunos de todo o ensino médio. A aplicação foi posta em prática para dois grupos, um composto por 30 alunos da turma de $3^{\circ}$ ano do ensino médio, e a segunda com grupos envolvendo estudantes do $1^{\circ}, 2^{\circ}$ e $3^{\circ}$ Anos juntos.

A prática na turma com 30 não foi como esperávamos, pois, o total de indivíduos na mesma atividade a tornou ineficaz. É essencial que cada aluno tenha a oportunidade de ver e manusear o experimento. As particularidades do experimento dessa aplicação foram semelhantes aquelas do "laboratório de demonstrações" (Filho, 2000), apresentando basicamente como objetivo: confirmar por meio dos experimentos os assuntos já abordados em sala de aula.

Sabe-se que os alunos precisam colaborar e interagir uns com os outros, especialmente ao manusearem experimentos. Por essa razão, a aplicação envolvendo grupos mistos de alunos, em quantidades de aproximadamente 10, foi mais eficiente no contexto deste trabalho.

O primeiro passo efetivado com os alunos, foram aulas sobre as principais características da plataforma Arduino, bem como foram mostrados vários componentes. $\mathrm{Na}$ sequência outras atividades iam sendo trabalhadas. Porém, antes da execução das atividades, o grupo de alunos era dividido em duplas ou trios. Com isso, todos realizavam as montagens 
experimentais. Obviamente, esses mini grupos poderiam trocar informações, visto que, enquanto uns realizavam as montagens no Arduino e na Protoboard, outros analisavam e editavam a programação no software do Arduino.

Essas interações são extremamente relevantes, pois a socialização do que é compreendido influi no desenvolvimento dos alunos. As ocasiões de progresso da atividade são momentos oportunos para mediação do professor, uma vez que pode surgir situações em que o professor necessite atuar na zona de desenvolvimento proximal (ZDP) do aluno (Oliveira, 2010), conforme discutido na seção de metodologia deste trabalho. Claro que os diálogos entre os membros das equipes também são oportunos para o desenvolvimento, as contribuições individuais somam-se e muitas vezes tornam-se esclarecedoras para o grupo e consequentemente para seus componentes. Esses últimos aspectos citados, referentes à interação social, encontram fundamentos na concepção de distribuição social da mente, teoria fundada na tradição de Vygotsky (Pereira et al., 2012)

As aplicações permitiram analisar a relevância da proposta e fazer correções nas atividades. Nestas aplicações, para a execução de uma atividade gastou-se em média 90 minutos, todavia, é importante que o professor deixe à disposição dos alunos todos os materiais necessários à montagem.

Os encontros ocorreram uma vez por semana no laboratório de Física da escola, durante três meses. No primeiro encontro, com duração de 90 minutos, eram apresentadas as funcionalidades do Arduino. No segundo encontro, com duração também de 90 minutos, ocorria a execução do experimento, indicada a uma dupla ou trio de alunos. No fim do segundo encontro, foram levantados os seguintes questionamentos:

1. Por que a mesma massa apresenta pesos diferentes em cada corpo celeste?

2. Como calcular a constante elástica para diferentes molas?

3. Calcule a aceleração gravitacional em cada corpo celeste usando a massa que você usou e os respectivos pesos apresentados.

4. Pense e comente sobre como a gravidade influencia na órbita de um corpo celeste.

Os alunos tinham uma semana para pesquisarem e reverem os dados experimentais coletados e finalmente compor soluções para apresentação no terceiro encontro. Logo, o tempo mínimo de dedicação dos alunos envolvidos era o de três encontros.

Foi notável que as aulas iniciais de apresentação e aplicação das atividades foram rígidas quanto ao andamento delas, predominando o caráter tradicional de ensino. Todavia, a partir do terceiro encontro a proatividade dos alunos foi ressaltada, onde a atuação docente 
foi de estimular e orientar, entretanto deixando a critério do aluno o que realizar e o modo de conduzir as ações do projeto, do qual são os autores. Essa liberdade permitida ao aluno pode ser desconfortante para o educador, porém é importante destacar que essa permissividade induz à motivação intrínseca, mais efetiva que a motivação externa (Arias, 2004).

A postura do professor em virtude das ações dos alunos, não deve ser de relaxamento. Se o aluno poderá ter seu próprio modo de execução da pesquisa, o professor não deverá despreocupar-se quanto à elaboração de um plano de ensino e qual a melhor forma para sua realização. O professor deverá preparar seu plano e no progresso das atividades ter subsídio para orientar, principalmente em relação a falta de certas competências do aluno. Para assumir essa postura o professor deverá observar e acompanhar muito bem seus alunos, o que lhe permite atuar nos momentos críticos de aprendizagem. Aqui a tarefa é um tanto complexa para a realidade de muitos professores, pois a atenção requerida para atuar em uma possível ZDP é individualizada; isso em razão da mediação do professor ser distinta para cada aluno (Miranda, 2005).

As aplicações do experimento para os grupos reduzidos apresentaram-se bem satisfatória, observou-se um interesse genuíno pelos temas das atividades, notavelmente pela inclusão do Arduino nos experimentos. Além da influência dos dispositivos eletrônicos, Arduino e sensores, foi relevante a liberdade nas ações dos experimentos, principalmente na aplicação do conhecimento adquirido.

A natureza dinâmica e criativa dos jovens envolvidos nas atividades foi preponderante para o sucesso das atividades, desde a simples realização das tarefas básicas propostas até idealização de novos projetos, envolvendo o que foi compreendido.

Todos os experimentos foram automatizados com os recursos do Arduino e seu componentes. A automação dos experimentos consistiu em captar, processar e exibir dados referentes às grandezas físicas, úteis na análise e assimilação de princípios físicos.

Levando em conta que as condições de montagem dos experimentos influenciam nos resultados, podendo divergir entre um ou outro, o que necessariamente não compromete o experimento.

Cada aluno envolvido nas atividades escreveu um depoimento, expressando suas impressões sobre as atividades. Em uma análise geral dos depoimentos, expressaram quão motivadora foram as atividades, objetivo importante do experimento. Os depoimentos foram propositadamente não identificados, quanto à autoria. Isso para que sentissem liberdade ao se expressarem. Nos parágrafos seguintes é destacado alguns trechos dos depoimentos dos 
alunos, os trechos são transcrições, mantidas as possíveis incorreções gramaticais e ortográficas.

Sobre a motivação, relata um dos alunos, que as aulas foram significativas para uma maior motivação em Física e também experiências de vida. A diversidade imposta nas atividades foi fator importante para essa motivação, tanto que um outro aluno destaca no seu depoimento: As aulas (..) são muito interessantes pois estimulam muito o nosso aprendizado de várias formas, no trabalho em equipe, (...).

Alguns alunos consideraram as atividades interessantes por contribuir no aprendizado, um deles escreve que as atividades ajudam a melhorar o desempenho do aluno na sala de aula. Muitos desses alunos atribuem essa contribuição à parte prática.

Notaram também que a automação dos experimentos ajudou no entendimento da disciplina de Física, considerada complicada para alguns alunos, conforme trecho em um dos depoimentos.

As atividades, pela sua natureza experimental em envolver a Física e dispositivos eletrônicos, traz novas impressões pessoais sobre a disciplina de Física, impressões que aproximam o aluno de uma cultura científica. Um aluno, que provavelmente tinha certa antipatia pelas aulas de Física, declara: $O$ curso de Física me ajudou olhar para disciplina por outro lado um lado legal onde aprendi de uma forma melhor. O curso também me abriu outras portas de conhecimento. É certo que as “outras portas de conhecimentos" referem-se às tecnologias resultantes dos conhecimentos sobre Física e das descobertas produzidas pelas novas tecnologias.

O total de alunos que participaram das atividades foi de 40 alunos, nesses dois anos de oferta. A escola, onde ocorreram os testes, é um escola de Ensino Médio da rede pública do Estado do Ceará, com matrícula total de 819 alunos em 2017, segundo dados da secretaria escolar; e 784 alunos em 2016, cujas taxas de rendimento para esse ano foram de 11,2\% de reprovação, $6,1 \%$ de abandono e $82,7 \%$ de aprovação, conforme informações do INEP (Brasil, 2016), presentes no Gráfico 1. 
Gráfico 1 - Taxa de rendimento da Escola Liceu de Tianguá em 2016, segundo censo escolar 2016.

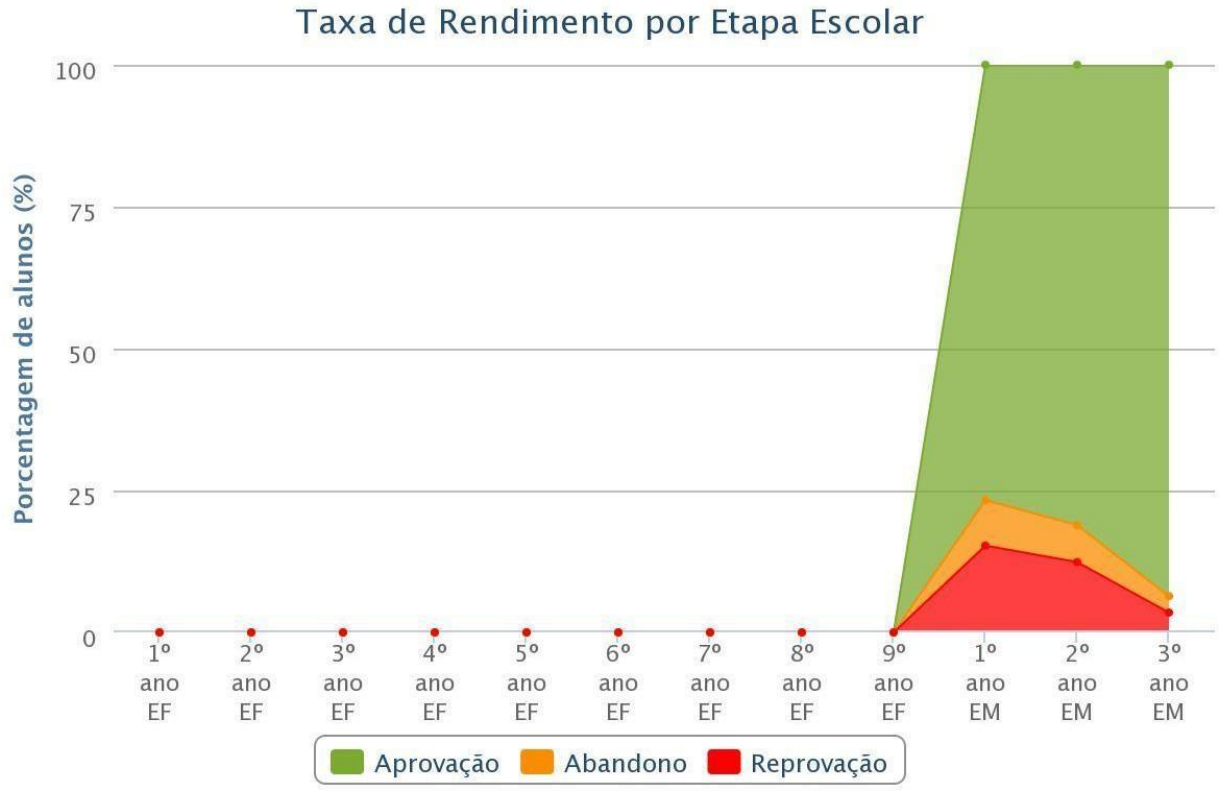

Fonte: Instituto Nacional de Estudos e Pesquisas Educacionais Anísio Teixeira. (Brasil, 2016).

Os índices apresentados para o ano de 2016 não são satisfatórios, indicando a necessidade de redefinições pedagógicas. Para a implementação do experimento, a fim de analisar a relevância das atividades, é um cenário ideal para testes, uma vez que a escola necessita da inclusão de novas ferramentas educacionais.

Obviamente, o foco da aplicação das atividades do experimento não foi produzir resultados imediatos no rendimento escolar no âmbito da disciplina de Física, mas verificar a relevância do projeto para uma possível implementação progressiva. As possíveis contribuições no rendimento da escola, em virtude da aplicação do experimento poderão ser futuramente analisadas.

\section{Considerações Finais}

A partir do que foi visto e discutido neste trabalho, é possível pensar na aquisição de dados como uma metodologia capaz de auxiliar o processo de ensino e aprendizagem de Física, levando a uma aprendizagem significativa, isto é, será capaz de gerar uma aprendizagem duradoura que sirva de base para o aprendizado futuro do aluno de Ensino Médio ou de Ensino Superior e também do professor que, através da pesquisa, vai adquirir conhecimentos práticos 
que somente o ensino "livresco" não seria capaz de promover. Além disso vale salientar que o professor pode utilizar este método de trabalho, como uma das possíveis formaa de realizar transposição didática.

Os resultados obtidos foram muito significativos, uma vez que foi possível vislumbrar outras faces da Física. Uma Física do cotidiano, uma Física por trás dos equipamentos eletrônicos que povoam nossas vidas e uma Física experimental associada com tecnologias modernas e não acessíveis aos professores e alunos das escolas de Ensino Médio, pelo menos por enquanto. Considera-se que, ao término desse trabalho, que é o resultado de projetos de Iniciação Científica, conhecimentos relevantes foram adquiridos.

Os alunos bolsistas de Ensino Médio relataram que, com exceção da eletricidade básica (que já conheciam, em parte), foram apreendidas noções de programação, microcontroladores, sensores e os conhecimentos avançados de Física aplicada nos sensores. Em termos mais técnicos, considerando a perspectiva do professor orientador, foi possível avançar em termos de aplicação da tecnologia Arduino na física experimental didática, visando o ensino de Física no Ensino Médio, Superior e, por que não, Fundamental. Foi possível vislumbrar inúmeras aplicações didáticas a serem desenvolvidas na continuidade do trabalho de pesquisa.

\section{Referências}

Arias, J. D. (2004). Perspectivas recientes en el estudio de la motivación: la Teoría de la Orientación de Meta. Revista Electrónica de Investigación Psicoeducativa, 2(1), 35-62.

Carvalho, J. C. N., \& Everton, N. B. (2020). Didactic sequence for the study of the concepts of Mechanics using Arduino. Research, Society and Development, 9(9), e26996542. https://doi.org/10.33448/rsd-v9i9.6542

Carvalho, L. R., \& Amorim, H. S. (2014). Observando as marés atmosféricas: Uma aplicação da placa Arduino com sensores de pressão barométrica e temperatura. Revista Brasileira de Ensino de Física, p. 7pp.

Chevallard, Y. (2013). Sobre a teoria da transposição de didática: algumas considerações introdutórias. Revista de Educação, Ciências e Matemática, III(3), 1-14. 
Cordova \& Tort (2016) \Cordova, H. .., \& Tort, A. (2016). Medida de g com a placa Arduíno em um experimento simples de queda livre. Revista Brasileira de Ensino de Física, 38 (2).

Dewey, J. (2015). Las fuentes de la ciencia de la educación. (A. O. Marquéz, Trad.) Barcelona: Lapislàtzuli Editorial.

Fernandes Sobrinho, M., \& Carneiro, M. (2015). Newton e a decomposição da luz solar em um prisma: o que trazem os livros de ensino médio?. Revista de ensino de Ciências e Matemática, 5(2), 35-55. https://doi.org/10.26843/rencima.v5i2.894

Filho, J. d. (2000). Regras da Transposição didática Aplicadas ao Laboratóro didático. Caderno Catarinense de Ensino de Física, 17 (2), pp. 44-58.

Fontele, F. F. M., \& Carvalho, J. C. N. (2020). Didactic sequence for the teaching of gravitational waves and interference in high school. Research, Society and Development, 9(9), e365997087. https://doi.org/10.33448/rsd-v9i9.7087

Miranda, M. I. (2005). Conceitos centrais da teoria de Vygotsky e a prática pedagógica. Ensino em Re-Vista. (13), 07-28.

Monk, S. (2014). 30 Projetos com Arduino (2 ed.). Porto Alegre: Bookman.

Oliveira, M. K. (2010). Vygotsky: Aprendizado e desenvolvimento Um processo sócio-histórico (5 $5^{\text {a }}$ ed.). São Paulo: Scipione.]

Pereira, A. P., Ostermann, F., \& Cavalcanti, C. J. (2012). Um exemplo de "distribuição social da mente” em uma aula de Física Quântica. Ciência \& Educação, 18(2), 257-270.

Valadares, J. (2011) A teoria da aprendizagem significativa como teoria construtivista. Aprendizagem Significativa em Revista, 1(1), 36-57.

Vygotsky, L. (2007). A formação social da mente: o desenvolvimento dos processos psicológicos superiores ( $7^{\mathrm{a}}$ ed.). São Paulo: Martins Fontes. 
Research, Society and Development, v. 9, n. 8, e844997733, 2020

(CC BY 4.0) | ISSN 2525-3409 | DOI: http://dx.doi.org/10.33448/rsd-v9i8.7733

Zanella, A. V. (1994). Zona de Desenvolvimento Proximal: análise teórica de um conceito em $\begin{array}{llllll}\text { algumas } & \text { situações } & \text { variadas. } & \text { Acesso } & \text { em }\end{array}$ em http://pepsic.bvsalud.org/pdf/tp/v2n2/v2n2a11.pdf.

Porcentagem de contribuição de cada autor no manuscrito

João Cláudio Nunes Carvalho - 50\%

Oséias de Sousa Mourão - 50\% 